\title{
Perception as a propositional attitude
}

\author{
(Lapercepción como una actitud proposicional)
}

\author{
Daniel E. KaLPOKAS* \\ Universidad Nacional de Córdoba/IdH, CONICET-UNC
}

\begin{abstract}
It is widely held that the content of perceptual experience is propositional in nature. However, in a well-known article, "Is Perception a Propositional Attitude?" (2009), Crane has argued against this thesis. He therein assumes that experience has intentional content and indirectly argues that experience has non-propositional content by showing that from what he considers to be the main reasons in favour of "the propositional-attitude thesis", it does not really follow that experience has propositional content. In this paper I shall discuss Crane's arguments against the propositional-attitude thesis and will try to show, in contrast, that they are unconvincing. My conclusion will be that, despite all that Crane claims, perceptual content could after all be propositional in nature.
\end{abstract}

KEYWORDS: Crane, propositional-attitude thesis, perceptual experience, propositional content, non-propositional content, accuracy conditions.

RESUMEN: Se sostiene, en general, que el contenido de la experiencia perceptiva es de naturaleza proposicional. Sin embargo, en un bien conocido artículo, “Es la percepción una actitud proposicional?” (2009), Crane ha argumentado en contra de esta tesis. Asumiendo que la experiencia tiene contenido intencional, él argumenta indirectamente que la experiencia tiene contenido no proposicional mostrando que, a partir de las que él considera que son las mejores razones en favor de "la tesis de la actitud proposicional", no se sigue realmente que la experiencia tenga contenido proposicional. En este artículo discuto los argumentos de Crane contra la tesis de la actitud proposicional y muestro, en contraste, que no son convincentes. Mi conclusión es que, a pesar de todo lo que dice Crane, el contenido perceptivo podría ser, después de todo, de naturaleza proposicional.

PALABRAS CLAVE: Crane, tesis de la actitud proposicional, experiencia perceptiva, contenido proposicional, contenido no proposicional, condiciones de adecuación.

\footnotetext{
* Correspondence to: Daniel E. Kalpokas. Instituto de Humanidades, Facultad de Filosofía y Humanidades, Universidad Nacional de Córdoba, Ciudad Universitaria, s/n, Pabellón Agustín Tosco, Córdoba, 5000, Argentina - dkalpokas@gmail.com - https://orcid.org/0000-0001-61376990
}

How to cite: Kalpokas, Daniel E. (2020). «Perception as a propositional attitude»; Theoria. An International Journal for Theory, History and Foundations of Science, 35(2), 155-174. (https://doi.org/10.1387/theoria.20574).

Received: 11 February, 2019; Final version: 24 July, 2019.

ISSN 0495-4548 - eISSN 2171-679X / (C) 2020 UPV/EHU 
It is widely held that the content of perceptual experience is propositional in nature. Let us call this claim about perceptual content "the propositional-attitude thesis". However, in a well-known article, "Is Perception a Propositional Attitude?" (2009), Crane has argued against it. He therein assumes that experience has intentional content and indirectly argues that experience has non-propositional content by showing that from what he considers to be the main reasons in favour of the propositional-attitude thesis, it does not really follow that experience has propositional content. In this article I shall discuss Crane's arguments against the propositional-attitude thesis and will try to show, in contrast, that they are unconvincing. My conclusion will be that, despite all that Crane claims, perceptual content could after all be propositional in nature. The relevance of a discussion of Crane's article nowadays lies, I believe, not only in that Crane critically examines there, in a clear way, two classical arguments for the propositional-attitude thesis (something that is not often in the present literature), but also in that, in that paper, he advances a thesis that currently is in the centre of much discussion, i.e., that perception is non-propositional (see Grzankowski \& Montague, 2018). For these reasons, I believe that Crane's article deserves a closer attention than the one it has received.

The structure of the article is as follows. After presenting the propositional-attitude thesis [section 1], I will briefly reconstruct Crane's arguments [section 2]. Then, I shall critically examine these arguments in order to show that, based on them alone, we cannot conclude that perception does not have propositional content [section 3]. After this, in order to reinforce this conclusion, I will introduce a well-known argument in favour of the propositional-attitude thesis that has not been considered by Crane. This argument lends positive support to the idea that experience may, after all, have propositional content [section 4]. The final section summarizes the results of the previous discussion [section 5].

\section{The propositional-attitude thesis}

As Crane correctly notes, it is widely accepted nowadays that perceiving is a propositional attitude like believing or intending. The following pair of quotations can serve to illustrate this point. ${ }^{1}$

Searle, for example, claims that "The content of the visual experience, like the content of the belief, is always equivalent to a whole proposition. Visual experience is never simply of an object but rather it must always be that such and such is the case" (Searle, 1983, p. 40). In addition, McDowell, in turn, states that "in a particular experience in which one is not misled, what one takes in is that things are thus and so. That things are thus and so is the content of the experience, and it can also be the content of a judgment" (McDowell, 1998, p. 26). ${ }^{2}$

Although these two philosophers hold slightly different conceptions about what perceptual experience is, both believe that the content of experience is propositional in nature.

1 I mention recent works here, but see Wittgenstein (Tractatus, 5.5423) and Sellars (1997, p. 40). Sellars (1967) changed his view about the propositional content of experience in favour of a conception according to which perceptual content is demonstrative.

2 For other statements of this view, see Tye (1995); Glüer (2014); Byrne (2005), and Peacocke (1983). Peacocke (1992a, 1992b) and McDowell (2009) abandoned the propositional-attitude thesis. 
The notion of propositional content crucially depends on the way one takes propositions to be. As is well-known, the term "proposition" has a broad and disparate use in contemporary philosophy. In his article, Crane adopts what he takes to be the usual understanding of propositional content, or propositions, as the bearers of truth-value, the meanings of indicative sentences, the referents of that-clauses and the relata of truth-functional logical relations.

Moreover, Crane notes that the term "content", such as it appears in notions like "intentional content", "propositional content" and "content of experience", belongs within the theory of intentionality. Intentional mental states (hopes, beliefs, experiences, fears, etc.) typically have objects and contents. It is commonly claimed that the object of an intentional state is the item towards which the state is directed. For example, in a state of desire there is something that is desired. What is desired is the object of the desire. In the case of belief, the object of a belief is what it is about, and so on. In some cases, the object of an intentional state might be something that does not or cannot exist (e.g. a centaur or a squared-circle). But in other cases, the object of an intentional state actually exists. In these cases, the intentional object is an ordinary, real thing or state of affairs.

According to Crane, there are three important reasons for introducing the idea of content in addition to that of intentional object. Firstly, the object of a mental state can be represented in different ways, even when the mental states are of the same kind (belief, desire, etc.). The different ways in which an object is represented in a mental state are the aspects under which the object is represented. These aspects are what are usually called "the contents of intentional states". Secondly, even when a mental state is not directed toward any real object, there is something real in each intentional state: there is a representation of an object, whether that object is real or unreal. The way the putative object of a state is represented is said to be its content. Finally, intentional states can represent their objects in an accurate or inaccurate way. The fact that intentional states can be accurate or inaccurate is the third typical reason for introducing the notion of content.

Now, how is all this applied to the case of perceptual experience? As Crane points out, it can be plausibly claimed that perceptual experiences, like other intentional states, have objects and contents. Their objects are what is seen, what is heard and so on. And since different experiences of the same kind (visual, auditory, etc.) can differ regarding the aspect under which they present their objects; since they can also represent what does not exist (for instance, in case of hallucination) and, finally, since they can be accurate or inaccurate (think of the distinction between veridical, illusory and hallucinatory experiences), it can also be held that experiences have intentional contents. The content of experience, then, is said to be equivalent to the way, or aspect, according to which the world is perceptually presented. Crane's challenge is directed not toward the very idea of perceptual content but rather to a particular way of understanding it, i.e., as being propositional in nature. ${ }^{3}$

3 Recently, some philosophers have questioned the very idea that perceptual experience has intentional content. See Brewer (2006, 2011); Travis (2004); Campbell (2002); Johnston (2006); Raleigh (2013), and Fish (2009). Responses to this line of thought can be found in McDowell (2013); Ginsborg (2011), and Schellenberg (2011). In this paper I shall assume, as Crane and many other philosophers do, that experience does, in fact, have representational content. 


\section{Crane's objections}

In his article, Crane begins by noticing that those who think perception is a propositional attitude often point to the fact that experiences have accuracy conditions (see, for example, Searle, 1983). An experience is accurate in this sense if and only if it has an actual object which is as the experience represents it as being. In this view, the content of the experience is the proposition which gives the way the object of the experience is represented as being. For example, when I see the grey cat on the mat (Crane's example), my experience represents it in a particular way. The experience is accurate if that is the way the cat and the mat really are. The content of the experience is, then, the proposition that the cat is on the mat.

It is worth noting here that the propositional-attitude thesis is not the thesis that perceptions are beliefs (Armstrong, 1968; Davidson, 2001; Glüer, 2009, and Byrne, 2009); rather, it is the idea that the content of experience is of the same kind as the content of belief or judgment. What one can judge or believe is a proposition, that is, something that is true or false. Since propositions are true or false, the propositional-attitude thesis states that the contents of experiences can also be true or false. Crane's objections, then, are specifically directed toward this thesis. Here is Crane's own thesis: "the content of experience is not propositional, and so it cannot be the kind of thing that can be the content of a belief or judgment" (Crane, 2009, p. 453). ${ }^{4}$

For his part, Crane does not directly argue for the claim that experience has non-propositional content; instead, assuming that experiences have intentional content, he argues against the propositional-attitude thesis and, thereby, concludes that this content is non-propositional in nature. This is the reason why his main thesis is only indirectly supported. So, schematically speaking, Crane's argument is as follows: (1) perceptual experiences have intentional content; (2) the intentional content of experiences can be propositional or non-propositional in character; (3) the main reasons that have been offered to

4 Despite this quotation, someone might think that it is not obvious that Crane's article is correctly understood as an attack on the propositional-attitude thesis; rather, it may be viewed as, merely, an attempt to block some arguments that have been assumed to force us to accept that thesis. At this point, I do not want to deny that such weaker reading is possible. From that reading, Crane would look more prudent than I think he is. However, I should say two things: first, I do not see that such weaker reading introduces any actual difference for my arguments in the present paper. I am arguing, mainly, that Crane's objections against two well-known arguments for holding the propositional-attitude thesis are not sound. Thus, it is not important whether Crane actually wants to reject the propositional-attitude thesis or, simply, he aims to block the arguments that have been proposed in favour of it. In any case, the propositional-attitude thesis remains standing and, as a result, there is no motivation for holding or suggesting that perception has non-propositional content. Second, there is further textual evidence that corroborates my reading. For example, Crane (2013b, p. 240) claims: "I have argued elsewhere that experiences have non-propositional content, in the sense that their fundamental way of representing the world is non-propositional". And here "elsewhere" explicitly refers to the paper I am criticizing. Still, in another place, Crane defends the idea that experience has non-propositional content. He claims: "Seeing, noticing, admiring, loving, liking — all of these states are directed upon objects under aspects. They do not have propositional contents" (Crane, 2013a, p. 105. See also pp. 103-104). Hence, I believe that Crane is actually committed with the idea that experience has non-propositional content and, therefore, with a rejection of the propositional-attitude thesis. 
support the thesis that experiences have propositional content are not sound at all; (4) in consequence, the contents of experiences are non-propositional in nature. ${ }^{5}$

In order to criticize the propositional-attitude thesis, Crane presents two lines of criticism, which correspond to the two arguments he considers to be the ones that mainly support the thesis in question. The first one focuses, with regards to a content, on the distinction between its being accurate or inaccurate on the one hand, and true or false on the other hand. Crane's second line of criticism points out that describing a certain kind of content in propositional terms does not actually imply that the content so described is propositional in nature. Let us examine each line of criticism in more detail.

Crane argues that, the mere fact that experiences can be accurate or inaccurate is not sufficient to conclude that they can be true or false (Searle, 1983, p. 41, seems to make this mistake). Crane holds that: "Accuracy is not truth since accuracy admits of degrees and truth does not” (Crane, 2009, p. 458). For example, a picture-Crane says-can be more or less accurate, but it is not true or false. In contrast, a proposition cannot be more or less true. Truth and falsehood do not admit degrees; they are all or nothing. ${ }^{6}$ Thus, since what are true or false are propositions, Crane concludes that the argument from accuracy-conditions does not support the idea that perceptual experiences have propositional content.

Moreover, the possibility of being true or false is central to the idea of a proposition since truth and falsehood (and not merely adequacy and inadequacy) are the semantic concepts of propositional logic. Truth-functions operate on propositions: propositions can be negated, disjoined and conjoined; in contrast, pictures cannot stand in logical relations to each other: they cannot be negated or disjoined, for example. In this sense, Crane argues, experiences are like pictures: "if a proposition were the content of a perceptual experience, then it should be capable of being negated, disjoined, conjoined, etc. But it seems that just as one cannot do these things to the content of pictures, one cannot do them to the contents of experiences either", (Crane, 2009, p. 462). Crane's conclusion is, then, that perceptual experiences can only be accurate or inaccurate (but not true or false) and that they cannot stand in logical relations to each other. This is Crane's first line of criticism.

Nevertheless, the propositional-attitude theory may be defended in another way. It may be conceded that the content of a picture cannot be asserted, negated, disjoined, etc., but it could still be argued that there can always be a sentence that has the same content as a picture: the sentence could accurately describe what a picture represents and how it represents it. Since sentences which express propositions can effectively be asserted, negated, disjoined, etc., then, to the extent to which the content of pictures could be described by sentences, it could be claimed that their contents can, after all, stand in logical relations to one another. And similar considerations may also be applicable to the case of experience.

However, Crane argues that "describing the content and being the content are not the same thing" (Crane, 2009, p. 460). The content of a representation is how its object is represented. Content in this sense could be described in many ways. According to Crane,

5 In the light of recent discussions about the non-propositional character of some attitudes, it is important to highlight here that Crane's thesis is that experience has representational non-propositional content. His thesis is not, then, that experience is, merely, a certain kind of attitude directed towards objects.

6 Crane does not justify the comparison (intuitive only in the case of visual experiences) between experiences and pictures. 
then, one can represent the condition for the correctness of a representation (e.g. a picture) by means of a sentence without the representation itself being sentence-like. Therefore, even if a sentence gives the content of a representation, this is not enough to make this representation propositional in nature. Now, by exploiting the analogy between pictures and perceptual experiences, Crane concludes that the same point can be made for the case of experiences: describing their contents in propositional terms does not entail that experiences themselves are propositional in character. This is Crane's second line of criticism to the propositional-attitude theory.

\section{Objections to Crane's objections}

Crane's arguments are interesting and certainly shed new light on some problems about perceptual content; in my view, however, they are unconvincing. Let us consider his first line of criticism. It is true that, as Crane observes, the fact that experience has accuracy-conditions is not sufficient to conclude, without more qualifications, that experience has truth-conditions. However, neither does this, by itself, imply that the content of experience is not true or false and, thus, that experience is not a propositional attitude. There is not a direct and simple inference which leads from the acknowledgment that accuracy is not equivalent to truth to the conclusion that experiences are not true or false; nor, consequently, to the thesis that experiences have non-propositional content. Let us examine this in more detail.

Crane believes that pictures, for instance, can be more or less accurate, but not true or false. In contrast, propositions are not more or less true. They are true or false, period. Analogously, he believes that experiences-which are, in his opinion, more or less accurate but not true or false-do not have propositional content. However, Crane explores neither the sense in which it may be said that a picture or experience can be accurate or inaccurate, nor the relation between truth and accuracy. In my view, these points deserve careful attention because it can be said, in a natural way, that both pictures and experiences can be, in one sense, true or false and, in another sense, accurate or inaccurate. ${ }^{7}$ Consequently, if one takes this into account, one can see that Crane's arguments do not actually suffice to undermine the thesis according to which perception has propositional content.

In effect, it should be noted that the terms "accurate" and "inaccurate" can be applied not only to pictures, but also to linguistic items, such as remarks and descriptions. For instance, it could be said that a description is more or less accurate depending on the amount of true propositions it includes. In this sense, it may be sensibly claimed that a description that only includes true propositions is more accurate than one that also includes some false propositions. Regarding this sense in which descriptions can be said to be accurate or inaccurate, it is clear how truth and falsehood, on the one hand, and accuracy and inaccuracy, on the other, are related to each other: the accuracy of a description is a function of the amount of true propositions it involves.

I believe that similar considerations apply to the case of pictures. Admittedly, the content of pictures is very rich indeed. A picture of my room, for instance, could represent

7 Of course, pictures and experiences could be accurate or inaccurate in many ways. Here I assume that Crane uses the terms "accurate" and "inaccurate" in a representational sense. 
many things: where the door is located in reference to the window, the way its furniture is arranged, the shape of the desk, the objects that are on it, etc. However, this is no obstacle to claiming that its content is propositional. One could simply claim that the content of the picture is constituted by a set of propositions, one of which represents the way the furniture is arranged in the room, another of which represents how the desk is, and so on. So, for one thing, considering the bits, aspects or parts that compose the content of a picture, it could be said that they are true or represent with truth, or truly represent, a thing. The picture may truly represent, for example, the shape and colour of the desk. Hence, when we focus our attention on different aspects of the content of a picture, i.e., when we pay attention to the different propositions that compose the whole content of a picture, it could be claimed that they can be true or false. For another thing, however, in strict parallelism with what has already been claimed for the case of descriptions, it could be said that, depending on the amount of true aspects, or parts (i.e. propositions), of which the content of a picture is composed, the whole picture is more or less accurate or inaccurate. As in the case of descriptions, the accuracy of pictures could be a function of the truth of the parts that compose the whole content of them.

Similar considerations may be applied, I hold, to the case of perceptual experience. At this point it may be helpful to note that the content of perceptual experiences can, as happens in the case of the content of pictures, be very rich. In seeing a certain cup, one can simultaneously see its colour, shape, location, etc. In hearing a song, one can hear the singer's voice, the sound of the instruments, the lyrics, etc. In touching a table, one can sense the texture of its surface, its hardness, what shape it has, etc. In this sense, it could be thought that perceptual content is composed not of a single proposition (if we accept for the moment that perceptual content is propositional) but rather of a set of propositions (Peacocke, 1983, p. 5; McDowell, 1998, p. 49, n. 6). However, if we consider a specific aspect, or bit, of the content of a visual experience (e.g., the part of the content on which the attention is focused) I see no obstacle to claiming that this aspect of the experience is veridical, if this happened to be the case, or that this bit of the content of the experience is true. ${ }^{8}$ For example, if I needed to decide whether the cup of coffee that is in front of me is white or not, I could focus my attention on the colour of the cup and see whether the cup is white or not. Let us suppose that the cup is white and that I can perfectly see its colour. This is a case in which I may claim that my visual experience is veridical, or that its content is true.

But if we now consider the experience as a whole and take into account other aspects of the content of my experience of the cup, those which refer to the shape of the cup, the material with which it has been made, its location, etc., it may also be said that the experience is accurate or inaccurate depending on how many of these aspects are true or false. If the experience correctly represents every property of the cup on which I focused my attention, it could be claimed that my experience is completely veridical or that its content is completely accurate. However, it may be the case that my visual experience represents some properties of the cup correctly, whereas it misrepresents some others. Something of this sort is typical of visual illusions. For instance, let us consider the well-known case of

8 Sellars has no issue with the application of the term "truth" to the content of perceptual experiences. See Sellars (1997, p. 40). See also Siegel (2010, p. 28) and McDowell (1998, p. 162). 
the lines of Müller-Lyer illusion. Here it could be claimed that one's visual experience correctly represents the presence of two lines, whereas it misrepresents their length. A natural way of describing this situation for a defender of the propositional-attitude thesis would be to claim that the content of such illusory experience is composed, at least in part, by two propositions: the proposition that represents the presence of two lines, which is certainly true; and the one that represents their relative lengths, which is false. ${ }^{9}$ Similarly, my experience of the cup could be decomposed into several propositions (one that represents its shape, another that represents its location, and so on), some of which may be true and some others false. Thus, it could be claimed that an experience that represents every property of the cup truly (i.e. an experience in which all the propositions that compose its content are true), is more accurate than the experience that represents truly only some properties of the cup in question (i.e., an experience in which only some propositions that compose its content are true). ${ }^{10}$

The moral that should be drawn from this discussion is, I think, that nothing relevant to the question of whether perceptual content is propositional in nature or not can be obtained by distinguishing, as Crane does, between accuracy-conditions and truth-conditions. The distinction is certainly correct, but it does not prove that experience is not a propositional attitude, nor does it undermine the argument from the accuracy-conditions of experience: advocates of the propositional-attitude thesis may argue that the fact that experiences have accuracy-conditions is compatible with the view that experiences are both, in a certain sense, true or false and, in another sense, accurate or inaccurate. In fact, if my considerations on the content of experience are correct, the accuracy or inaccuracy of experience is a function of the truth or falsehood of the different aspects of its content. So there is an intrinsic connection between the fact (if it is actually a fact) that the different aspects of the content of experience can be truth or false, on the one hand, and the fact that this content is accurate or inaccurate, on the other hand.

9 See the treatment that Siegel gives to this topic in Siegel (2010, chap. 2). Matthen (2014) also holds that perceptual experiences can be both accurate or inaccurate, and true or false.

${ }_{10}$ Still, someone might argue that, for every part of its content, an experience can be more or less accurate. For example, let us consider the case in which, in looking at a light brown table, one visually experiences it, at different moments, as dark brown, as orange, or as black. Here, even though all these experiences would be wrong, one may rank them with respect to their degree of accuracy, e.g., considering that experiencing the table as dark brown is less inaccurate than experiencing it as black. To this challenge, however, the proponent of the propositional-attitude thesis can respond, I think, as follows: on the one hand, she can insist on the point that the crucial thing is that experience must help one to determine what colour the table is, and for this purpose, non-veridical experiences are equally inaccurate. The question "Is the table light brown?" is a Yes/No question, and seeing the table must help one to determine which answer is the correct one. For this purpose, then, any non-veridical experience leads one to the wrong answer. On the other hand, given certain purposes, perhaps one may rank those experiences according to their degree of accuracy, as the objection suggests. Nevertheless, it should be noted that something similar goes for sentences or propositions as well. In effect, it may also be said that the sentence "The table is dark brown", though false, represents the colour of the table less inaccurately than "The table is black". However, from this, it does not follow that sentences (or the propositions expressed by them) are not true or false but, rather, only more or less accurate. The same can be claimed for the case of experiences. I am indebted to an anonymous referee of Theoria for pressing this point. 
Crane's remark about the impossibility that pictures (and, assuming the comparison, experiences) can stand in logical relations to each other raises a more complicated issue. Crane's argument seems to be the following: propositions can be negated, disjoined, etc. But pictures cannot be pictorially negated, disjoined, etc. Therefore, pictures have no propositional content. And, Crane concludes, the same goes for the case of experience.

The topic of whether pictures have propositional content or not has been, and still is, a matter of dispute between philosophers (see Westerhoff, 2005; Heck, 2007; Matthen, 2014; Grzankowski, 2015), and I'm afraid that Crane does not sufficiently support his point of view. Fortunately, I do not need to fully enter into that debate, because Crane's argument, outlined in the previous paragraph, has an important flaw. In effect, as Grzankowski (2015) has recently pointed out, even if it is conceded that pictures cannot be negated, disjoined etc. without appealing to other non-pictorial resources, it does not follow from this concession alone that they do not have propositional content. It only follows that pictures cannot express certain kinds of propositions-negated, disjoined, etc. propositions-or, to express it more clearly, that pictures' content cannot be constituted by negated, disjoined, etc. propositions.

Similar considerations may be valid, I believe, for the case of perceptual experience. Even if it is conceded that experiences cannot stand in some logical relations to each other, or cannot include negated, disjoined, etc. propositions as their contents, it does not follow from this fact, at least without more argument, that the content of experiences is not propositional in character. It only follows that a certain kind of propositions-negated, disjointed, etc. propositions - cannot be the content of perceptual experiences. But, what is the argument for not believing that experiences have propositional contents such as this is a book or this book is red? Certainly, there is a gap here in Crane's argument. Thus, it seems that the possibility that perception has such kind of propositional content remains untouched by Crane's argument. The alleged impossibility of having experiences with negated, disjoined, etc. propositions may be explained, as Crane suggests for the case of pictorial content, by appealing to the particular kind of vehicle of perceptual content. However, this is consistent with attributing propositional content to experiences, because one can still believe that perceptual vehicles are suitable for carrying propositions that do not include any logical connectors.

Let us now consider Crane's second line of criticism. Remember that, according to Crane, from the claim that the content of experience can always be described in a sentence that expresses a proposition, it does not follow that experience in itself has propositional content. ${ }^{11}$ Crane seems to crucially assume here that whatever the nature of perceptual content might be, a sentence can adequately describe it. Therefore, he seems to reason, describing perceptual content in propositional terms should not be taken as a sign that such content is propositional in character. However, Crane's assumption can be questioned.

${ }^{11}$ In the article I am considering here, he uses the case of loving to illustrate his point. He claims that although Napoleon's love for Josephine is a case of an intentional non-propositional state, there is a sentence "which describes the content of Napoleon's love, i.e., describes what he loves and the way in which he represents her", (Crane, 2009, p. 463). The sentence is, according to Crane, this: "There is someone who is identical with Josephine" (Crane, 2009, p. 463). Now, according to Crane, this sentence describes the content of Napoleon's love, "without being the content of his love" (Crane, 2009, p. 463). 
Since Crane does not tell us what his conception of perceptual non-propositional content is, I will appeal to some well-known examples in the literature about that topic. ${ }^{12}$ Indeed, non-propositional content may be construed in different ways: for instance, as scenario content (Peacocke, 1992a, 1992b); as intuitional content (McDowell, 2009); or in terms of mediational content (Cussins, 2003). However, in contrast to what Crane seems to assume, in none of these cases would it be easy to describe the putative non-propositional content of experience in propositional terms. The general reason of this is straightforward: in describing in propositional terms the supposed non-propositional content of experience, whatever its variety may be, we would inevitably distort the nature of such a kind of content. In effect, the three examples of non-propositional content recently mentioned are, in so far as they are non-propositional, contents in which there are no predicates. In all of them, though for different reasons, it is not the case that a predicate is said to be applied (or denied) with truth or falsity, to a certain subject. As a result, though it may be said that they are contents which can be correct or incorrect in a certain sense, one could not say they are true or false. But then, it seems that to describe such kinds of contents by means of sentences, which express propositions, would be invariably to ascribe a wrong structure to them. It would be as if we were talking about contents that may be true or false, when, in fact, such contents cannot have truth-values at all. Thus, if this were the case, our reports of the contents of our experiences would be systematically misleading. In such a case, it would not be appropriate to claim, as Crane does, that sentences can adequately describe the contents of perceptual experiences. If my reasoning is correct, sentences would not be suitable devices to describe, or express, the supposed non-propositional content of experience, whatever its variety might be. ${ }^{13}$

${ }^{12}$ In another place, Crane provides some examples of what he considers to be cases of non-propositional content: imagining a horse neighing (Crane, 2013a, p. 101), and a dog represented as threatening in a feeling of fear towards it (Crane, 2013a, p. 102). Although these examples are not examples of perceptual non-propositional content, they may give us some cues about what kind of content he has in mind. However, these examples are open to dispute. Why should we accept that imagining a horse neighing or representing a dog as threatening in a feeling of fear are examples of intentional mental states with non-propositional content? The advocate of the propositional attitude thesis could say that, insofar as a subject knows what she is representing, she is imagining that a horse is neighing, or that a dog is threatening. Although these brief remarks do not settle the question, they suggest, I think, that more effort is needed to demonstrate that Crane's examples are cases of non-propositional content.

${ }_{13}$ Presumably, this is the reason why advocates of non-propositionalism do not typically use sentences to describe the putative non-propositional content of experience. For example, McDowell (2009, p. 270) appeals to complex demonstrative expressions, such as "This red cube", in order to express the supposed intuitional content of experience. In this case, it is clear, I think, that to express that kind of content in propositional terms would distort the nature of such content (it would misleadingly suggest, for example, that perceptual content represents states of affairs when, according to McDowell, it only represents objects). Similar considerations may be valid for the case of Cussins's mediational content. As Cussins (2003) characterizes it, this kind of content does not represent states of affairs at all. It is, rather, a kind of knowing how. It presents the world, not as a truth-maker, but "as an environment that mediates activity in the environment' (Cussins, 2003, p. 155). What Cussins calls 'the realm of mediation' consists of 'the trails that distinguish patterns of afforded activity from patterns of resisted activity' (Cussins, 2003, p. 155). The world experienced as the realm of mediation guides us in our ac- 
Of course, if perception had propositional content, sentences could describe it in a suitable way. In seeing that a cup is on the table, for example, we could describe, or make explicit, the content of our perception by using the sentence, "The cup is on the table". Thus, I believe that advocates of the propositional-attitude thesis could perhaps insist on their point: from the fact that there can always be a sentence that describes perceptual content, it does follow that such a kind of content is propositional in nature because if such content were non-propositional, it could not be properly described by sentences at all. ${ }^{14}$

At this point, it should be clear that, if experiences were not credited with propositional contents of any kind, we could not logically operate on their contents even when these were expressed linguistically. In effect, the advocate of the propositional-attitude thesis can argue that, since negation and conjunction, for example, operate on propositions, it would perfectly make sense to claim, in the appropriate contexts, things like these: "Things are not as they visually appear!", or "I saw that the book was on the table and that John took it." In an ordinary understanding of what is expressed by these sentences, what is negated in the first sentence and put in conjunction in the second one are propositions. Thus, if we think that sentences are suitable devices to express the propositional content of experiences, we can logically operate on such contents after all (even when it is conceded to Crane that experiences cannot have negated propositions, etc., as their contents). In contrast, if experiences were credited with non-propositional content, we could not logically operate on the linguistic expressions of them. In effect, the proper linguistic expression of such kind of contents would presumably be given, not by complete sentences but, rather, by a part of them (e.g., by attributive expressions). But, then, under the assumption that

tivities in the environment. Correspondingly, Cussins assigns two different sorts of normativity to conceptual/propositional and non-conceptual/non-propositional contents. Conceptual/propositional contents are constitutively governed by the norm of truth; in contrast, non-conceptual/non-propositional contents are governed by 'mundane normativity', 'the gentle bumpings of one's body and informational systems; the cognitive affordances and resistances of the environment' (Cussins, 2003, p. 154). So, as in the case of McDowell's intuitional content, it seems that mediational content could not be properly grasped by a sentence (or set of sentences). The content of sentences can be true or false, it typically makes reference to objects and properties in the world, and it aims to represent states of affairs. Nothing similar can be said about mediational content. Finally, Peacocke's scenario contents are spatial types, i.e. ways of locating surfaces, features, etc., in relation to a labelled origin and a family of axes. Peacocke is clear about why he believes that "a purely propositional account" cannot properly explain the representational content of experience: (i) it is parasitic "on something properly treated by use of scenarios" (Peacocke, 1992b, p. 113) and (ii) it makes impossible "an adequate account of the first-person way of thinking" (Peacocke, 1992b, p. 114). It is not merely the case that, according to Peacocke, perceptual content is not propositional in character; it is also that linguist descriptions cannot properly grasp the putative scenario content of experience: "we have on this account to recognize the rather indirect way in which descriptions in ordinary language $[\ldots]$ help to characterize the way someone is experiencing the world. The ordinary-language characterization of the scenario can be at most partial" (Peacocke, 1992b, p. 111).

${ }^{14}$ Indeed, it may be argued that our ordinary practice of attributing perceptual experiences to others reflects the idea that experience has propositional content. We commonly say things of the following kind: "She saw that John took the book". Sellars (1997, $₫$ IV) holds that, in such a case, we not only attribute an experience with propositional content, but that, also, we endorse that content (i.e., we take it as true). 
the linguistic devices that are suitable to express the putative non-propositional content of experiences are not sentences, we will lose the possibility to logically operate on them. This is a high cost to pay for the rejection of the propositional-attitude thesis. ${ }^{15}$

But let us suppose now that Crane's crucial assumption is correct, i.e. that whatever the nature of perceptual content might be, it could be properly described by a sentence, or a set of sentences. Even in this case, Crane's argument does not support, even indirectly, his thesis that experience has non-propositional content. In effect, it should be noted that from the mere fact that there is a distinction to make between describing the content and being the content, it follows neither that perception has propositional content nor that it has non-propositional content. Crane's argument, if it is correct, only shows that there is no direct and necessary implication between describing perceptual content in propositional terms and that content being propositional in nature. Thus, advocates of the propositional-attitude thesis should not use the fact that perceptual content may be described in propositional terms as an argument in favour of their thesis. However, Crane's objection does not show, at least by itself, that perceptual content is non-propositional in nature, either. The way in which we describe perceptual content is neutral with respect to its nature. In fact, it may still be the case that perceptual content is, after all, propositional, and this fact could explain, in part, why we commonly use sentences in order to describe it. So if we accept Crane's second line of criticism, we can only conclude that the fact that perceptual content may be described in propositional terms is not a good reason to believe that such content is propositional in nature. However, we cannot conclude, even indirectly, that perceptual content is non-propositional. For this additional thesis, an independent and positive argument is still required. Thus, Crane's objection leaves open the question of whether perceptual content is propositional or not, and so his second line of criticism does not show, in itself, that the content of experience is non-propositional in nature.

We are at an impasse here: from the fact that the content of experience can be described by a sentence we can conclude neither that experience has propositional content nor that it has non-propositional content. The problem is that Crane believes that his arguments support a negative answer to the question that appears in the title of his article ("Is perception a propositional attitude?"). However, if I am right, he has provided us with no compelling reason to agree with him. Crane's objections to the propositional-attitude thesis leave untouched the possibility that experience has propositional content. For the same reason, it can be claimed that there is no genuine motivation to believe that experience has non-propositional content.

\section{An argument for the propositional-attitude thesis}

I have argued so far that the idea that perceptual experiences have accuracy conditions (the idea that experiences can be more or less accurate) is perfectly compatible with the idea

15 In the Introduction to Grzankowski \& Montague (2018, p. 16), these authors (two advocates of the non-propositional character of some intentional mental states) acknowledge that non-propositionalists need, crucially, a logic that shows us how to treat the logical relations between (propositional and) non-propositional mental states. 
that their contents can be true or false. Moreover, in contrast to Crane's position, I have pointed out that the fact that perceptual content can be described or made explicit by a sentence or a set of sentences, may be proposed as a genuine reason to believe that perceptual content is propositional in nature. Finally, I have argued that even in case this last reason were dismissed, the fact that perceptual content may be described in propositional terms does not tell us anything regarding the nature of perceptual content. Therefore, we cannot conclude, then, even indirectly, that such kind of content is non-propositional in character.

But is there another positive motivation (besides those discussed by Crane) to believe that experience has propositional content? It is, of course, impossible to settle this question here, but what I want to do instead is to present a certain line of thought in favour of the propositional-attitude thesis, which has not been considered by Crane. The proposal consists of considering some roles (epistemic and other ones) that are commonly attributed to perceptual experience and then asking what kind of content the experience must have in order to be able to play these roles. Although this strategy is not completely novel, it has not been taken into consideration by Crane and, for this reason, it deserves, I believe, close attention here. The existence of that strategy not only indicates a lacuna in Crane's critical examination of the grounds for holding the propositional-attitude thesis, but also it suggests a close connection with the argument from accuracy-conditions defended in the previous section of this article.

It is widely accepted that, among others (Schellenberg, 2016), experience has, at least, the following intuitive roles: (1) providing epistemic reasons for empirical judgments and beliefs (McDowell, 1998; Brewer, 1999; Ginsborg, 2011); (2) making possible to understand demonstrative expressions, ${ }^{16}$ and (3) providing reasons for behaving one way rather than another. Now, it could be plausibly argued that, in order to be able to play these intuitive roles, experience must have propositional content. I take this to be a strong motivation to accept the propositional-attitude thesis.

In order to illustrate my point, I can only consider here the first intuitive role of perceptual experience (1). Imagine that I want to know whether a certain cup is white or not. An obvious way of knowing this would consist of looking at the cup and seeing whether it is white or not. Let us suppose that, in fact, it is white. As a consequence of seeing the colour of the cup, I come to believe, or judge, that the cup is white. Now, let us suppose that I am asked why I believe, or judge, that the cup is white. Here, a natural answer could be "Because I see that the cup in question is white". In this case, it seems to be crucial that the content of my visual experience is propositional in character, because if it is actually so, it is easy to explain how my experience could be a reason to believe, or judge, that the cup is white. ${ }^{17}$

In effect, if experiences are to be reasons at all, their contents must be able to be in the relevant logical (inferential or non-inferential) relations with the contents of judgments

16 See Brewer (1999); Evans (1982); Campbell (2002). I do not want to imply here that Evans and Campbell are advocates of the propositional-attitude thesis. I merely mention them as authors that attribute to experience an essential role in the understanding of demonstrative thoughts and expressions.

17 There has been some discussion about what reasons are. See, for example, Alvarez (2010); Turri (2009); Ginsborg (2006). Since my specific topic is delimited by the discussion of Crane's point of view about whether experiences - assuming that they have non-propositional content- could be reasons at all, I do not need enter that debate here. 
and beliefs. Now, if the content of my experience is constituted by the proposition that this cup is white, the truth of this proposition could be non-inferentially transmitted, by the mere identity transition of the contents, to the truth of my belief or judgment. ${ }^{18}$ In such case, the transition from my experience to my judgment or belief could be warranted by the very nature of the contents at play (McDowell, 2009, p. 131). If the proposition that constitutes the content of my experience is true, the transition will warrant that my judgment or belief will be true as well.

In contrast, and as many philosophers have argued (Huemer, 2001; Thau, 2002; Lyons, 2008; Ginsborg, 2011; Rosenberg, 2002; Glüer, 2014), if experience had non-propositional content (whatever this kind of content might be), it would be very difficult to see how experience could be a reason to judge or believe that things are such and such a way. Although those philosophers are not explicit at this point, I think that the ultimate reason for the difficulty is straightforward: non-propositional content (if there actually is such a kind of content) does not seem to be suitable to be a bearer of truth-value; and as a consequence, it seems inapt to stand in the required logical relations (inferential or non-inferential) to the contents of judgments and beliefs. ${ }^{19}$ In effect, whatever this kind of content might be, it would surely lack a predicate; but without a predicate, it seems that this kind of content could be neither true nor false and, consequently, it could not represent states of affairs at all. ${ }^{20}$ So, it seems that the identity transition of contents, which was taken as a model to understand the case of non-inferential justification when experience is credited with propositional content, cannot work here.

As an example, let us consider McDowell's proposal, with which Crane (2013b) ${ }^{21}$ sympathizes, according to which the intuitional content of a visual experience may be expressed

${ }^{18}$ In more complex cases, the content of the experience could make the truth of a judgment or belief more probable. For the idea that perceptual experiences non-inferentially justify judgments and beliefs, see McDowell (2009, p. 131).

19 The common thread among the authors mentioned above is the idea that rational justification is inferential. However, if, as I claim, what is at play here is, ultimately, the truth of the justificatory items, then, propositional content is needed for non-inferential justification as well.

${ }^{20}$ Of course, there are nominalized clauses that can refer, in a certain sense, to states of affairs or facts. In our case, it may be thought that 'the fact that the cup is white' could express the non-propositional content of an experience. So, although this does not seem to be Crane's idea, one may argue that non-propositional contents can, after all, represent states of affairs or facts. But, in fact, this possible replica does not work. Nominalized clauses do not represent, in the relevant sense, states of affairs or facts; they do not describe them, but, instead, name them. For this reason, nominalized clauses, such as 'the fact that the cup is white', cannot be true or false. They can only refer to or fail to refer to the relevant fact.

${ }^{21}$ In that article, although he mainly deals with the nature of perceptual content, Crane also makes some by-passing references to the problem of justification. Reconstructing the debate between McDowell and Travis, Crane comes to claim that "I see no obstacle to the claim that seeing something [in Travis's sense] can justify one's judgment", (Crane, 2013b, p. 232). Thus, Crane implies (at least in that passage) that, in order to justify a judgment, experience does not need to have conceptual content, as McDowell holds, nor even any other kind of content (this is Travis's claim). However, this misunderstands the accusation of falling into the Myth of the Given, directed by McDowell against Travis. According to Travis, seeing a pig, say, under an oak is simply an awareness of some portion of the visible reality. If we have the concept of a pig, then we can judge that the pig is under the oak on the basis of that experience plus our ability to recognize that what we experience is an instance of a thing of a cer- 
by a demonstrative expression such as, for instance, "This red cube". McDowell explicitly holds that this kind of content does not represent a state of affairs but, rather, an object (McDowell, 2013, p. 154). Now, how could this kind of content be true or false? And without the possibility of being true or false, how could it be a reason at all? It is true that McDowell insists on the idea that experiences can be reasons for belief (McDowell, 2009, p. 270); however, it should be noted that not only the model of non-inferential justification indicated above, based on the identity transition of contents, does not apply here, but also, and crucially, that it is not clear at all how perceptual states that represent mere objects could rationally justify propositional attitudes, such as empirical judgments and beliefs, which represent states of affairs.

Although McDowell is not explicit at this point, it might be thought that, when he holds that experience with intuitional content can be a reason for belief or judgment, he has in mind something as the following: judgment unpacks and articulates the unarticulated and packed intuitional content of experience. Thus, if the intuitional content of an experience can be expressed by the demonstrative expression "This red cube," one may articulate, based on that content, the following two judgments: (i) "This is a red cube," and (ii) "This cube is red." Therefore, McDowell perhaps believes that, in this sense, the experience of this red cube can be a reason for judgments (i) and (ii). However, why should we accept that articulating and unpacking, in judgments (i) and (ii), the intuitional content of that experience is a reason-giving relation $?^{22} \mathrm{~A}$ reason is often considered to be "a consideration that counts in favor of" (Scanlon, 1998, p. 17) something else (a judgment or belief). Why should we take the intuitional content this red cube as a consideration in favor of the truth of (i) and (ii)? The content this red cube is not a case of this is thus and so; thus, it can be neither true nor false. It is not, properly speaking, a complete content-one may saybut, rather, a part of a content. Since the putative content expressed by "this red cube" cannot be true or false, then, it cannot help us to judge that (i) and (ii) are true, or probably true. So, an experience with the alleged content this red cube should not be considered to be a move in the logical space of reasons. As a result, it seems quite implausible to think that perceptual representations of objects, which cannot be true or false, can be reasons to be-

tain kind. For McDowell, this is a case of the Myth of the Given, because the mere presentation, in experience, of a pig does not count as an epistemic or cognitive state. In order to be able to judge that the pig is under the oak on the basis of our experience, the pig has to be seen as a pig and as being under the oak. If experience does not disclose the pig as a pig, we lack any basis for recognizing the pig as an animal of a certain kind. Recognition is something that takes place in experience itself; otherwise, it is too late for being the basis of a judgment. In other words, one cannot recognize that what one experiences is an instance of a thing of a certain kind (e.g., a pig), if one's experience does not disclose to one the relevant thing as being a thing of a certain kind. This is the reason why McDowell insists on the idea that experience has conceptual content. In any case, the idea that a physical object (e.g., a pig) can rationally justify a judgment is, I think, so untenable as the idea that states with non-propositional content can do that: as a non-propositional content, an object is neither a bearer of truth-values.

${ }^{22}$ A similar problem is apparent in Heck (2000). Heck holds that perceptual content is non-conceptual and, presumably, non-propositional. In trying to explain how experience could justify a judgment or belief, he claims that the content of a judgment "tracks" the content of the relevant experience. He also uses the terms "conceptualize", "translate", and "reflect" in order to characterize the epistemic relation between a judgment and an experience. However, none of these terms refers to a reason-giving relation. See Kalpokas (2018). 
lieve or judge that certain propositions are true or false. The failure of the identity transition of contents between experiences and beliefs is a failure in the transition of the relevant properties (e.g., truth-values) that seem to make possible the relevant rational relation between the contents of experiences and beliefs..$^{23}$

Moreover, and for similar reasons, it seems that experiences, when they are credited with non-propositional content, cannot justify beliefs and judgments inferentially either. ${ }^{24}$ In effect, an argument typically requires premises (i.e. bearers of truth-value) from which a conclusion (i.e. another bearer of truth-value) can be drawn. But non-propositional contents cannot be true or false (let us remember that this is the point of Crane's first objection to the propositional-attitude thesis). Thus, they are not apt to be premises from which to infer any conclusion. Lacking the possibility of being true or false, perceptual non-propositional content cannot transmit, deductively or inductively, the property of being true to the relevant conclusion.

I can express my point in still simpler terms: it is commonly assumed that empirical judgments and beliefs represent, when they are true, empirical facts. In this sense, if it is conceded that, for example, a certain cup's being white is a fact, then, it can be claimed that the fact that the cup is white makes the belief, or judgment, that the cup is white to be true. If perceptual experience is credited with propositional content and this content is the same as the content of the relevant belief or judgment, then, it can be claimed that the proposition "That cup is white", which figures in the content of the experience, represents such a fact. So, the account about how perceptual experiences can be reasons for their corresponding beliefs or judgments is very simple: the very same content that is provided by experience is endorsed in the relevant judgment or belief. In contrast, if the propositional content of experience is conceived as different from the relevant belief (e.g. "That object of such and such form is white"), the experience could rationally justify the correspondent belief inferentially. However, if experience had non-propositional content, i.e., if it did not represent facts when it is veridical but, rather, objects, scenes or whatever variety of non-propositional content might be, perceptual content could be neither a non-inferential, nor an inferential reason to

${ }^{23}$ Although I do not have space here to consider in detail other examples, I would like to mention the case of Peacocke, who claims: "Experiences give a thinker who possesses the relatively observational concept square not merely reasons but good reasons for forming the belief that the demonstratively presented object is square' (Peacocke, 1992a, p. 80). Peacocke makes this statement only once he has introduced, besides the level of scenario content, the level of proto-propositional content, a level in which one is able to perceive something as a square, for instance, or as a regular diamond; so it is sensible to think that Peacocke actually believes that it is this level of perceptual content the one that, crucially, makes possible for experience to be a reason for the relevant belief. (Indeed, it could be argued that the mere perceptually representation of a square surface, say, in an egocentric space does not amount to representing that surface as having the property of being square. On this point, see Castellano, 2018). However, it could be legitimately thought here that, after all, Peacocke's proto-propositions are not quite different, structurally speaking, from propositions, i.e. conceptual contents of the form "a is P" (see Castellano, 2018). So, it seems that, insofar as Peacocke's perceptual non-conceptual content is non-propositional in nature, then it cannot be a reason for belief; and, conversely, insofar as it can be a reason for belief, it must be propositionally structured.

${ }^{24}$ Even when someone might believe that it is implausible to apply the inferentialist model of justification to experience, this is, of course, a possible theoretical alternative. Raleigh (2016) argues against that inferentialist model. 
hold the relevant judgment or belief about the cup. Thus, it seems that one would be obliged to abandon the intuitive idea that perceptual experiences can be reasons at all. ${ }^{25}$

A similar reasoning may be applied to other aspects of the content of perceptual experience. For example, besides the fact that the cup in question is white, my experience of the cup reveals to me, crucially, the presence of the cup itself. The fact that there is a certain cup in front of me, over there, is something that my experience of the cup also discloses to me. This is the way I know that there is a certain cup in front of me. I would not be able to see that a certain cup is white if, at the same time, I did not see that this cup is present to me (or that there is a certain cup over there). The presence of the cup in front of me is something that is represented by my experience (Searle, 1983, p. 40). Thus, if we believe that experience has propositional content, how I can perceptually know that there is a certain cup in front of me could be naturally explained: the propositional content of my experience represents that fact. And as in the previous case, if experience in fact has propositional content, seeing that there is a certain cup in front of me could be a reason to judge that there is a certain cup in front of me.

In contrast, let us suppose that experience, due to its non-propositional content, does not reveal to us what there is in the world. In this model of perceptual content, the content of experience would not be the sort of content that represents states of affairs such as that there is a cup in front of me. Then, how could one know that there is a certain cup in front of one? It seems that if this sort of state of affairs was not perceptually available, then the knowledge of it would need to be inferred in some way. However, this surely would be unattractive. Typically, in looking at a certain cup, one does not infer that there is a cup in front of one; rather, one directly sees that there is one. But even if this consideration were dismissed, another crucial difficulty would arise: as it has been argued above, non-propositional contents cannot figure as premises of any inference at all. Thus, if we suppose that experience has non-propositional content, then, an inference to the judgment or belief that there is a certain cup in front of one cannot have as a premise the content of one's experience. ${ }^{26}$ So, on this construal of the content of experience, experience could not be a reason to judge or believe that objects and their properties are present to the perceiver.

To sum up, if perceptual experience did not have propositional content, it would not represent, in the relevant sense, states of affairs such as that there is such and such object, property or event in front of us. For the same reason, experience could not represent states of affairs such as that a certain cup of tea is white, that the cup is to my left, etc. In such a case, as I have argued, experience could not be a reason to judge or believe that the world is such as experience represents it to be because it would be a capacity that it does not allow us to be in the appropriate epistemic contact with the relevant states of affairs, i.e. the states of affairs that are represented, or aim to be represented, by our judgments and beliefs. In other words, if experience had non-propositional content, a kind of content that cannot be true or false, it could not have the appropriate logical relations to judgments and beliefs, which

25 This is the path taken by Burge (2003). I argue against Burge's position in Kalpokas (2014).

26 At this point, it may be proposed that is not the putative non-propositional content of experience the one that figures in the required inference; instead, it is from the belief that one sees a certain cup in front of one that one can infer that there is a cup in front of one. However, in such case it would be clear that the experience itself could not be one's reason to judge or believe that there is a certain cup in front of one. 
are necessary to be epistemic reasons at all. ${ }^{27}$ As a result, it seems that Crane faces the following dilemma: either he holds that experience has non-propositional content, but then he must accept that he cannot accommodate the intuitive epistemic role of experience; or he acknowledges that experience has, in effect, that intuitive role, but then he must abandon his non-propositionalist thesis about the content of experience.

\section{Conclusion}

In this paper, I have discussed Crane's arguments against the propositional-attitude thesis. In my opinion, his arguments do not entitle us to abandon the propositional-attitude thesis nor to hold the opposite thesis: that experience has non-propositional content. The intertwined arguments presented in section 3 have had the purpose to show that Crane's objections to the grounds on which the propositional-attitude thesis is based are not sound, and that for this reason, the proposal that experience has non-propositional content is not adequately motivated. Moreover, as I have argued in the final section of this article, there is an important reason to accept the idea that experience has propositional content: if experience actually has propositional content, it is possible to explain, in an intuitive way, the roles that are commonly attributed to experience. This argument, which has not been considered by Crane, is perfectly consistent with the argument from the truth-conditions of experience, which does not prevent us, as I have argued in section 3, from simultaneously considering experiences to be more or less accurate. Of course, this line of thought deserves more development and refinement, and for this reason I do not claim to have definitely settled the problem of whether experience has propositional content or not. ${ }^{28}$ Notwithstanding this, I believe that the argument of appealing to the intuitive roles of experience not only looks promising, but also entitles us, especially when it is combined with my objections to Crane's objections to the propositional-attitude thesis, to preserve the idea that perceptual experience has propositional content. ${ }^{29}$

27 Similar considerations may be applied to the other roles of experience. Let us consider, for example, the second role of experience (2), namely, that of providing knowledge of the reference of demonstratives. Let us suppose that, in front of a certain book, you say "That book is wonderful!" In order to properly understand your exclamation, I have to be able to perceptually know what object you are talking about. But in order to do that, I have to be able to see that the relevant object is a book. Yet, this seems to require that experience has propositional content. Demonstrative expressions are properly understood when one perceives their referents. One cannot understand this kind of expressions without perceptually identifying their referents. But perceptually identifying something is to perceive it as such and such a thing or property, that is, to perceive that it is such and such object or property. Let us consider now the relation between experience and action. In order to form the intention of taking a certain cup, which is on the table, and correctly performing the act of taking it, I have to be able to see that there is a cup of tea on the table. Without this capacity to perceptually represent this state of affairs, it is hard to understand how I could be able to intentionally take the cup in question.

${ }^{28}$ For further discussion, see Raleigh (2016). At some points, Raleigh seems to believe, wrongly I think, that only non-propositional contents could provide non-inferential reasons for beliefs. For the idea that experience, having propositional content, non-inferentially justifies beliefs, see McDowell (2009, p. 131).

29 I am grateful to two anonymous reviewers of Theoria for their helpful comments and suggestions. 


\section{REFERENCES}

Alvarez, M. (2010). Kinds of reasons. Oxford: Oxford University Press.

Armstrong, D. (1968). A materialist theory of the mind. London: Routledge.

Brewer, B. (1999). Perception and reason. Oxford: Oxford University Press.

Brewer, B. (2006). Perception and content. European Journal of Philosophy 14, 165-181. doi: 10.1111/j.1468-0378.2006.00220.x

Brewer, B. (2011). Perception and its objects. Oxford: Oxford University Press.

Burge, T. (2003). Perceptual entitlement. Philosophy and Phenomenological Research LXVII, 503-548. doi: 10.1111/j.1933-1592.2003.tb00307.x

Byrne, A. (2005). Perception and conceptual content. In E. Sosa and M. Steup (eds.) Contemporary debates in epistemology (pp. 231-250). Oxford: Blackwell.

Byrne, A. (2009). Experience and content. The Philosophical Quarterly 59(236), 429-451. doi: $10.1111 /$ j.1467-9213.2009.614.x

Campbell, J. (2002). Reference and consciousness. Oxford: Oxford University Press.

Castellano, F. (2018). Non-conceptualism, observational concepts, and the given. Theoria 33(3), 401-416. doi: $10.1387 /$ theoria. 17829

Crane, T. (2009). Is perception a propositional attitude? The Philosophical Quarterly 59(236), 452-469. doi: $10.1111 /$ j.1467-9213.2008.608.x

Crane, T. (2013a). The objects of thought. Oxford: Oxford University Press.

Crane, T. (2013b). The Given. In J. Schear (ed.). Mind, reason, and being-in-the-world. The McDowell-Dreyfus debate (pp. 229-249). London: Routledge.

Cussins, A. (2003). Content, conceptual content, and nonconceptual content. In Y. Gunther (ed.). Essays on nonconceptual content (pp. 133-163). Cambridge: The MIT Press.

Davidson, D. (2001). Subjective, intersubjective, objective. Oxford: Clarendon Press.

Evans, G. (1982). Varieties of reference. Oxford: Oxford University Press.

Fish W. (2009). Perception, hallucination, and illusion. Oxford: Oxford University Press.

Ginsborg, H. (2006). Reasons for belief. Philosophy and Phenomenological Research 72(2), 286-318. doi: ppr20067228.

Ginsborg, H. (2011). Perception, generality and reasons. In A. Reisner \& A. Steglish-Peterse (eds.). Reasons for belief (pp. 131-157). Cambridge: Cambridge University Press.

Glüer, K. (2009). In defense of a doxastic account of experience. Mind \& Language 24(3), 297-327. doi: $10.1111 / j .1468-0017.2009 .01364 . x$

Glüer, K. (2014). Looks, reasons, and experiences. In B. Brogaard (Ed.). Does Perception Have Content? (pp. 76-103). Oxford: Oxford University Press.

Grzankowski, A. (2015). Pictures have propositional content. Review of Philosophy and Psychology 6(1), 151163. doi: $10.1007 / \mathrm{s} 13164-014-0217-0$.

Grzankowski, A. \& Montague, M. (eds.). 2018. Non-propositional intentionality. Oxford: Oxford University Press.

Heck, R. (2000). Non-conceptual content and the 'space of reasons'. The Philosophical Review 109(4), 483523. doi: 10.1215/00318108-109-4-483.

Heck, R. (2007). Are there different kinds of contents? In B. McLaughlin (ed.). Contemporary debates in the philosophy of mind (pp. 117-138). Singapore: Blackwell.

Huemer, M. (2001). Skepticism and the veil of perception. Lanham: Rowman \& Littlefield.

Johnston, M. (2006). Better than mere knowledge? The function of sensory awareness. In T. Gendler \& J. Hawthorne (eds.). Perceptual experience (pp. 260-290). Oxford: Clarendon Press.

Kalpokas, D. (2014). ¿Autorización perceptiva? Teorema XXXIII(1), 19-37.

Kalpokas, D. (2018). Non-conceptualism and the myth of the given. Dialectica 72(3), 331-363. doi: $10.1111 / 1746-8361.12234$. 
Lyons, J. (2008). Evidence, experience, and externalism. Australasian Journal of Philosophy 86(3), 461-479. doi: $10.1080 / 0004840000801886363$.

Matthen, M. (2014). Image content. In B. Brogaard (ed.). Does Perception Have Content? (pp. 265-290). Oxford: Oxford University Press.

McDowell, J. (1998). Mind and world. Cambridge: Harvard University Press.

McDowell, J. (2009). Having the world in view. Cambridge: Harvard University Press.

McDowell, J. (2013). Perceptual experience: both relational and contentful. European Journal of Philosophy 21(1), 144-157. doi: 10.1111/ejop.12005.

Peacocke, C. (1983). Sense and content. Oxford: Clarendon Press.

Peacocke, C. (1992a). A study of concepts. Cambridge: The MIT Press.

Peacocke, C. (1992b). Scenarios, concepts and perception. In T. Crane (ed.). The contents of experience (pp. 105-135). Cambridge: Cambridge University Press.

Raleigh, T. (2013). Phenomenology without representation. European Journal of Philosophy 23(4), 12091237. doi: 10.1111 /ejop. 12047.

Raleigh, T. (2016). Against an inferentialist dogma. Synthese 194(4), 1397-1421. doi: 10.1007/s11229-0151002-z.

Rosenberg, J. (2002). Thinking and knowing. Oxford: Oxford University Press.

Scanlon, T. (1998). What we owe to each other. Cambridge: The Belknap Press of Harvard University Press.

Schellenberg, S. (2011). Perceptual content defended. Nous 45(4), 714-750. doi: 10.1111/j.14680068.2010.00791.x.

Schellenberg, S. (2016). Perceptual particularity. Philosophy and Phenomenological Research 93(1) 25-54. doi: 10.1111/phpr.12278.

Searle, J. (1983). Intentionality. Cambridge: Cambridge University Press.

Sellars, W. (1967). Science and metaphysics. Atascadero: Ridgeview Company.

Sellars, W. (1997). Empiricism and the philosophy of mind. Cambridge: Harvard University Press.

Siegel, S. (2010). The contents of visual experience. Oxford: Oxford University Press.

Thau, M. (2002). Consciousness and cognition. Oxford: Oxford University Press.

Travis, Ch. (2004). The silence of the senses. Mind 113, 57-94. doi: 10.1093/mind/113.449.57.

Turri, J. (2009). The ontology of epistemic reasons. Noûs 43(3), 490-512. doi: 10.1111/j.14680068.2009.00715.x.

Tye, M. (1995). Ten problems of consciousness. Cambridge: MIT Press.

Westerhoff, J. (2005). Logical relations between pictures. Journal of Philosophy 102, 603-623. doi: 10.5840/ jphil20051021210.

Wittgenstein, L. (1921). Tractatus logico-philosophicus. (D. F. Pears \& B. F. McGuinness, Trans.). London: Routledge \& Kegan Paul.

Daniel E. Kalpokas is Associate Professor at National University of Córdoba and Independent Researcher at National Scientific and Technical Research Council. His areas of interest are: epistemology, philosophy of mind, philosophy of language, pragmatism and meta-ethics. He is the author of Richard Rorty $y$ la superación pragmatista de la epistemología and of many articles published in journals, such as Dialectica, Erkenntnis, Grazer Philosophische Studien, Transactions of the Charles S. Peirce Society, etc.

Address: Universidad Nacional de Córdoba/IdH, CONICET-UNC. Ciudad Universitaria, s/n, Facultad de Filosofía y Humanidades, Pabellón Agustín Tosco, Córdoba, 5000, Argentina. E-mail: dkalpokas@gmail.com 